\title{
Microwave Assisted Drug Delivery
}

Jónasson, Sævar Pór; Zhurbenko, Vitaliy; Johansen, Tom Keinicke

\section{Published in:}

Proceedings of XXXIth URSI General Assembly and Scientific Symposium (URSI GASS), 2014

Link to article, DOI:

10.1109/URSIGASS.2014.6929196

Publication date:

2014

Document Version

Peer reviewed version

Link back to DTU Orbit

\section{Citation (APA):}

Jónasson, S. P., Zhurbenko, V., \& Johansen, T. K. (2014). Microwave Assisted Drug Delivery. In Proceedings of XXXIth URSI General Assembly and Scientific Symposium (URSI GASS), 2014 IEEE.

https://doi.org/10.1109/URSIGASS.2014.6929196

\section{General rights}

Copyright and moral rights for the publications made accessible in the public portal are retained by the authors and/or other copyright owners and it is a condition of accessing publications that users recognise and abide by the legal requirements associated with these rights.

- Users may download and print one copy of any publication from the public portal for the purpose of private study or research.

- You may not further distribute the material or use it for any profit-making activity or commercial gain

- You may freely distribute the URL identifying the publication in the public portal

If you believe that this document breaches copyright please contact us providing details, and we will remove access to the work immediately and investigate your claim. 


\title{
Microwave assisted drug delivery
}

\author{
Sævar Pór Jónasson, Vitaliy Zhurbenko*and Tom K. Johansen \\ Technical University of Denmark, 2800 Kgs. Lyngby, Denmark \\ stj / vz / tkj@elektro.dtu.dk
}

\begin{abstract}
In this work, the microwave radiation is adopted for remote activation of pharmaceutical drug capsules inside the human body in order to release drugs at a pre-determined time and location. An array of controllable transmitting sources is used to produce a constructive interference at a certain focus point inside the body, where the drugs are then released from the specially designed capsules. An experimental setup for microwave activation has been developed and tested on a body phantom that emulates the human torso. A design of sensitive receiving structures for integration on a drug capsule is presented.
\end{abstract}

\section{Introduction}

In the year 2008, $48 \%$ of the people in the United States took at least one prescription drug in a single month. The prescription drug use had increased by 4\% compared to 1998 [1]. With current increasing intake of drugs, a more efficient and controllable way of delivering the drugs is of great interest.

Oral delivery of pharmaceuticals is the preferred method compared to intravenous injection because of lower costs, reduced risks associated with the injection, and higher patient compliance due to self-administration. However the traditional oral delivery faces several challenges such as low drug permeability (not to be confused with electromagnetic permeability) through the gastrointestinal epithelium [2,3] and degradation of the active pharmaceutical components in the stomach [4].

Inherently the problem with current drug delivery systems, e.g. in the form of pills is the limited external control of when the drug is dissolved and absorbed by the body. Typically, the drug release is controlled by the intestinal $\mathrm{pH}$ gradient and is therefore released over a large segment of the intestine. The drugs are coated with special protective coatings which dissolve at a certain $\mathrm{pH}$ value. The time and the location for the drug release is therefore difficult to control. For certain diseases such as schizophrenia and diabetes, dosing must be stable and reliable [5].

Pharmaceutical drugs taken orally are normally designed to release the drug in the small intestine because there, the drugs typically exhibit maximal absorption [6]. The small intestines are less than $3 \mathrm{~cm}$ in diameter [7, pp. 272].

A number of techniques have been developed to externally control the drug delivery. These include, but are not limited to, the use of ultrasound [8], light waves [9], magnetic fields [10] and radio waves below $100 \mathrm{MHz}$ [11]. Complex systems have also been integrated into a drug delivery module consisting of a receiving inductor, control circuitry chip and a drug delivery chip [12]. Each of these methods has its pros and cons.

The alternative method that described in this work is to focus microwave energy inside the human body to get localized high-amplitude fields. These are then used to activate the specially designed micro-containers.

\section{Microwave Activation of Drug Release}

The purpose of the described here microwave activation system is to provide a method of releasing drugs inside the body, unobtrusively, i.e. without disturbing a patient. The concept is illustrated in Figure 1, where one of the anticipated scenarios is shown. A person is lying on a bed, sleeping after having ingested numerous capsules that contain pharmaceutical drugs. At a certain time, and at a pre-determined location inside the human body, the microwave activation system focuses electromagnetic energy that opens the capsules and releases the medical drug.

Obviously, the essence of the external activation of pharmaceutical drugs with microwaves depends on the ability to induce electromagnetic power at certain areas inside the body. A documented side effect of being irradiated by electromagnetic waves is that unwanted heating of areas, other than intended, can occur. A method for reducing the side effects is, to superimpose electromagnetic waves from multiple sources, creating a focus point.

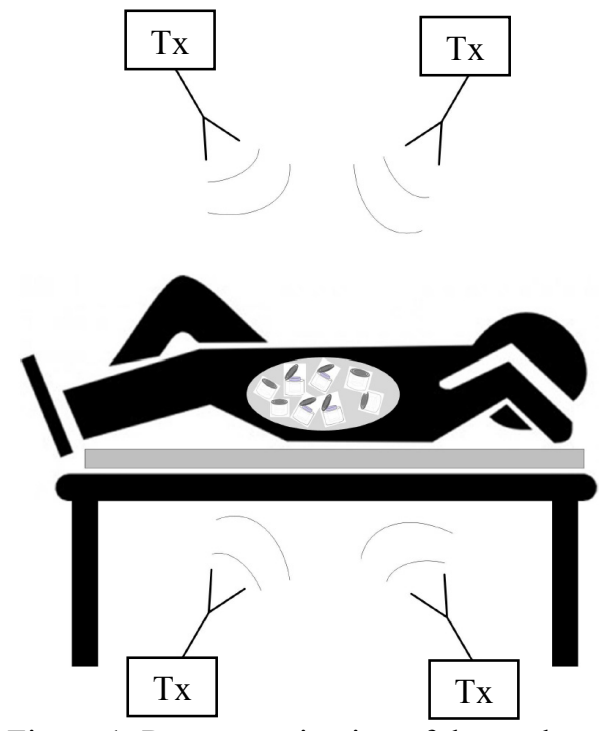

Figure 1. Remote activation of drug release using electromagnetic radiation. 
There are a number of critical design-choices to be made in a system that is to radiate electromagnetic waves inside the human body. These include operating frequency, number and location of transmitting antennas, pulsed vs. continuous wave operation, power level and flexibility of the system.

Generally with increasing frequency, attenuation in biological tissues increases and makes it more challenging to penetrate deeper into the body. Higher frequency signals, due to smaller wavelength, are able to focus onto smaller areas. Components, such as antennas, can be made smaller and that impacts the overall size of the system. Considering these tradeoffs, the operating frequency of the experimental setup described in this work has been chosen in ISM band and is approximately $2.45 \mathrm{GHz}$.

In Figure 2, a schematic drawing of the implemented setup is presented. A human torso phantom is in the center of the setup. To simplify the setup only four transmitters were implemented. They are evenly distributed around the phantom as it is shown in the Figure. Focusing of the electromagnetic energy is achieved by choosing the amplitude and phase of the transmitted signal. Microwave absorbers are placed in the plane of measurement, where one is placed behind each receiver and one between each receiver as shown in the Figure.

The submerged in the phantom sleeve dipole antenna (red dot in Figure 2) is mounted on the lid of the phantom and used as a probe for measuring the field distribution inside the phantom. The lid can be rotated $360 \mathrm{deg}$ in a continuous movement. The submerged antenna can also be moved continuously back and forth, from the centre of the phantom.

In the conducted experiments a number of arbitrary focusing points were pre-determined in order to examine the focusing abilities of the microwave activation system. The experimental data showed clear focusing points at the pre-determined locations for points less than $4 \mathrm{~cm}$ from the centre of the phantom, i.e. deep inside the lossy phantom. In those cases, the focus point is the highest amplitude-point across a diameter larger than $3.6 \mathrm{~cm}$. For comparison, the small

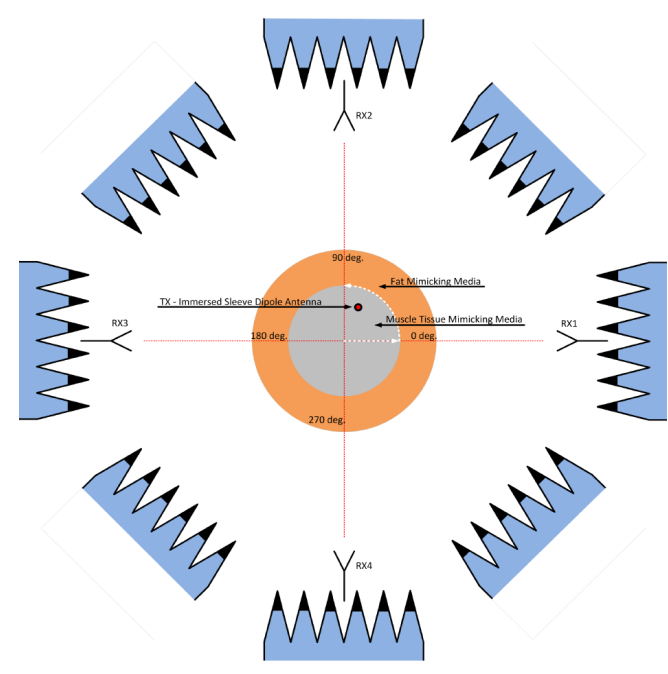

Figure 2. Schematic representation of the experimental setup. intestine in humans are typically less than $3 \mathrm{~cm}$ in diameter [7,

pp. 272] and is the place where the drug release is meant to take place. High-amplitude areas and spots (hot spots) appeared also at other locations than at the focusing point as was expected. This is a persistent problem in non-invasive hyperthermia systems as well. Increase of transmitting antennas should reduce the number of high-amplitude areas outside the focus area. A more detailed description and analysis of the achieved experimental results will be given at the conference presentation.

\section{Drug Capsule}

The inherent high losses of biological tissues at microwave frequencies make it challenging to penetrate deep into tissues with sufficient power levels. It is therefore required to have a very sensitive receiving structure on the drug capsule to absorb a significant part of the available power in order to use that energy to open the capsule. The anticipated scenario is illustrated in Figure 3 (a). A highly resonant structure, the split-ring resonator, is introduced on a lid of the capsule which contains a medicine. A resonator is able to induce locally high intensity fields at the resonance frequency, compared to other frequencies (refer to Figure 3. (b) and (c)) [13].

At the resonance frequency of the SRRs on the drug capsule structure, a relatively strong electric field is generated in the gaps of the rings and in the separation between them. The alternating field induces currents in the lossy dielectric lid where part of the electric currents are converted into heat, due to power loss (Figure 2(c)). This causes an increase of the temperature in the lid and by that, opens the capsule and releases the pharmaceutical drug. Practically, this can be accomplished by having the lid constructed of a polymer, which can abruptly change its adhesion, viscosity or permeability (a measure of the ability of a porous material to allow fluids to pass through it) when heated by just a few degrees. A layer of adhesive material, with a melting point several degrees above the ambient temperature, placed between the lid and the capsule could also operate as a release mechanism for the pharmaceutical drug. 


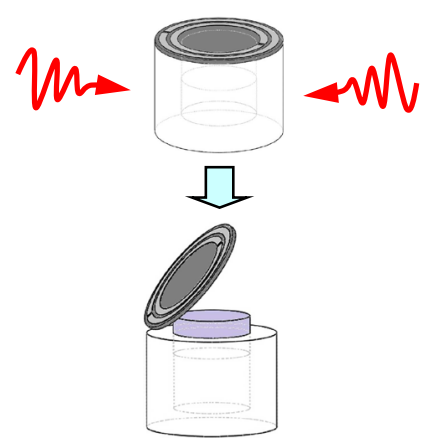

(a)

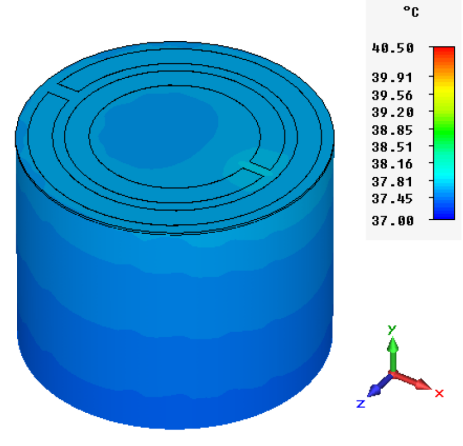

(b)

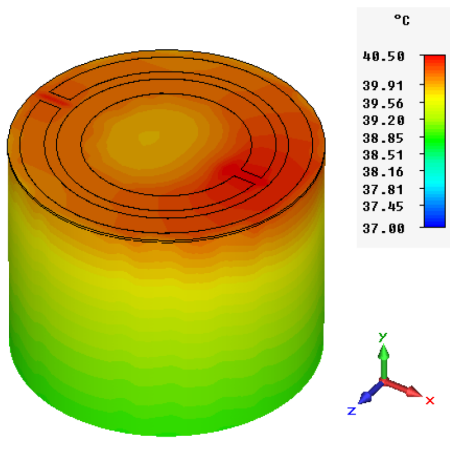

(c)

Figure 3. Illustration of the activation (opening) process. (a) - Split-ring resonators on a lid on top of a capsule and a drug being released. (b) and (c) - Temperature distribution of the capsule as a result of a power loss in the lid. (b) represents the temperature distribution at $2.3 \mathrm{GHz}$ and (c) at $2.43 \mathrm{GHz}$. Notice the difference in temperature.

The analysis in [13] shows the existence of an optimal complex permittivity of the lid material which results in the highest temperature rise.

\section{Summary}

In this work, a method of remotely activating and releasing pharmaceutical drugs inside the human body with the use of microwaves was investigated. Current limitations in external control of the specific location and the time of a drug release inside the human body formed the motivation for this study. The microwave activation system was developed on the basis of being an unobtrusive system, i.e. without disturbing the prospective patients. Four external antennas were designed to irradiate the torso phantom along with four microwave transmitters.

The measurement results revealed the wave behavior in the cylindrical phantom and the challenges of the focusing process. Even though focusing in the central part of the body can be achieved using the present setup, surface waves excited on the body-air interface disturbed the focusing of electromagnetic energy further away from the center of the body.

It was also found that by optimizing the complex permittivity of the capsule lid, one can maximize temperature increase in the lid. The temperature increase can then be used to melt the lid and release the drugs.

\section{Acknowledgments}

The authors would like to thank the Villum Kann Rasmussen Fonden for the partial financial support of the study.

\section{References}

1. Qiuping Gu, Charles F. Dillon, and Vicki L. Burt. Prescription drug use continues to increase: U.s. prescription drug data for 2007-2008. NCHS Data Brief, 42:1-8, 2010.

2. Kristy M. Ainslie, Rachel D. Lowe, Tristan T. Beaudette, Lamar Petty, Eric M. Bachelder, and Tejal A. Desai. Microfabricated devices for enchanced bioadhesive drug delivery: Attachement to and small-molecule release trhough a cell monolayer under flow. Small, 24:2857-2863, 2009.

3. Colin W. Pouton. Formulation of poorly water-soluble drugs for oral administration: Physicochemical and physiological issues and the lipid formulation classification system. European Journal of Pharmaceutical Sciences, 29:278-287, 2006.

4. Sanjay B. Bari, Bharati R. Kadam, Yogini S. Jaiswal, and Atul A. Shirkhedkar. Impurity profile: Significance in active pharmaceutical ingredient. Eurasian Journal of Analytical Chemistry, 2:32-53, 2007.

5. Anja Boisen. Naanomechanical sensors and actuators, fundamentals and new direction (namec) - a vkr center of excellence. NAMEC Project proposal to the VKR Foundation.

6. David R. Friend. Drug delivery to the small intestine. Current Gastroenterology Reports, 6:371-376, 2004.

7. Nazmul Akunjee and Muhammed Akunjee. The Easy Guide to OSCEs for Final Year Medical Students. Radcliffe Publishing Ltd., 2007.

8. Holger Grull and Sander Langereis. Hyperthermia-triggered drug delivery from temperature-sensitive liposomes using mri-guided high intensity focused ultrasound. Journal of Controlled Release, 161:317-327, 2012.

9. Cornelius Diamond and Scott Arouh. Light-activated drug delivery method and device. Patent, 2003. US 2003/0191458 A1.

10. Jean Brault. Magnetic apparatus used for drug delivery. Patent, 2011.WO2011113140 (A1).

11. Somayyeh Rahimi, Elie H. Sarraf, Gregory K. Wong, and Kenichi Takahata. Implantable drug delivery device using frequency-controlled wireless hydrogel microvalves. Biomedical Microdevices, 13:267-277, 2011. 
12. S. Smith, T.B. Tang, J.G. Terry, J.T.M. Stevenson, B.W. Flynn, H.M. Reekie, A.F. Murray, A.M. gundlach, D. Renshaw, B. Dhillon, A. Ohtori, Y. Inoue, and A.J. Walton. Development of a miniaturised drug delivery system with wireless power transfer and communication. IET Nanobiotechnology, 1:80-86, 2007.

13. Jónasson, Sævar Pór, Jensen, Brian Sveistrup, Johansen, Tom Keinicke, "Study of split-ring resonators for use on a pharmaceutical drug capsule for microwave activated drug release," Proceedings of European Microwave Conference 2012, pp. 76-79. 